\title{
The frame optimization and validation of resistance spot welding gun
}

\author{
Ji-Su Hong ${ }^{1}$, Kwang-Hee Lee ${ }^{2}$, and Chul-Hee Lee ${ }^{2, *}$ \\ ${ }^{1}$ Department of Construction Machinery Engineering, Inha University 100 Inharo, Michuholgu, Incheon 22212, South Korea \\ ${ }^{2}$ Department of Mechanical Engineering, Inha University 100 Inharo, Michuholgu, Incheon 22212, South Korea
}

Received: 2 August 2019 / Accepted: 1 September 2020

\begin{abstract}
Resistance spot welding gun is generally used to bond parts in the automotive and consumer electronics industries. In the automotive industry, chassis assembly operations use resistance spot welding. High production speeds allow for mass production and automation, resulting in diverse uses of resistance spot welding. To automate the welding process, it is mounted on a multi-joint robot and the welding gun is designed considering the specifications of the robot. High-strength structural design is needed to prevent deformation during pressurization, but the weight of the weld gun affects the efficiency of the robot. For this reason, it is necessary to design a welding gun with high stiffness and light weight. In this study, the analysis is carried out to measure the stress and deformation amount of weld gun. Optimization for weight reduction is performed by genetic algorithm method and topology optimization. The optimization of the resistance spot weld gun frame is performed, and the optimized model is verified through experimental verification. The production cost of industry has been reduced through the high stiffness and light weight of welding gun.
\end{abstract}

Keywords: Resistance spot welding gun / size optimization / topology optimization / structural stress / experimental validation

\section{Introduction}

Resistance spot welding (RSW) is widely used for the joining of sheet metal parts such as the manufacture of automobiles, trucks, buses, automotive electrical appliances, aircraft structures, and many other products $[1,3]$. Resistance spot welding is widely used because of its high production speed and mass production and automation. More than $90 \%$ of the assembling work in the automotive industry is completed by RSW. To cope with various welding conditions such as automobile and other industries, the RSW gun is attached to the multi-joint robot. Figure 1 shows a typical example of the RSW gun attached to a multi-joint robot. As various welding conditions occur in consideration of the shape of the welding member, the shape of the welding gun has various shapes. For efficiency, various types of welding are possible through the modular frame design, and the modular frame is welded by $\mathrm{C}$ type, $\mathrm{X}$ type according to the welding situation.

Research on RSW has been carried out on welding process, welding nugget size, parameter optimization, and thermal analysis, which affect welding quality [3-7].

\footnotetext{
* e-mail: chulhee@inha.ac.kr
}

The RSW gun used in the present component joining is designed considering the high safety factor compared to the required specifications. Since the weight of the welding gun is continuously increased due to the need of high pressing force, the payload of the multi-joint robot also increases so that the specifications of the multi-joint robot are determined more than necessary. The stress and the amount of deformation transferred to the structure when the welding is performed have a significant influence on the quality of the welding [8]. The problem mentioned above becomes possible to use the low-specification multi-joint robot by reducing the production cost and reducing the payload of the multi-joint robot by reducing the weight of the welding gun structure. In this study, the frame structure optimization and the experimental verification of the resistance spot welding gun are performed to reduce the weight of the welded structure.

\section{Finite element analysis}

\subsection{Finite element model and material}

Analysis and optimization of RSW guns use Ansys Workbench 2019 R2. The shape of the RSW consists of frame, arm, two tips, two holders, and motor assembly, 


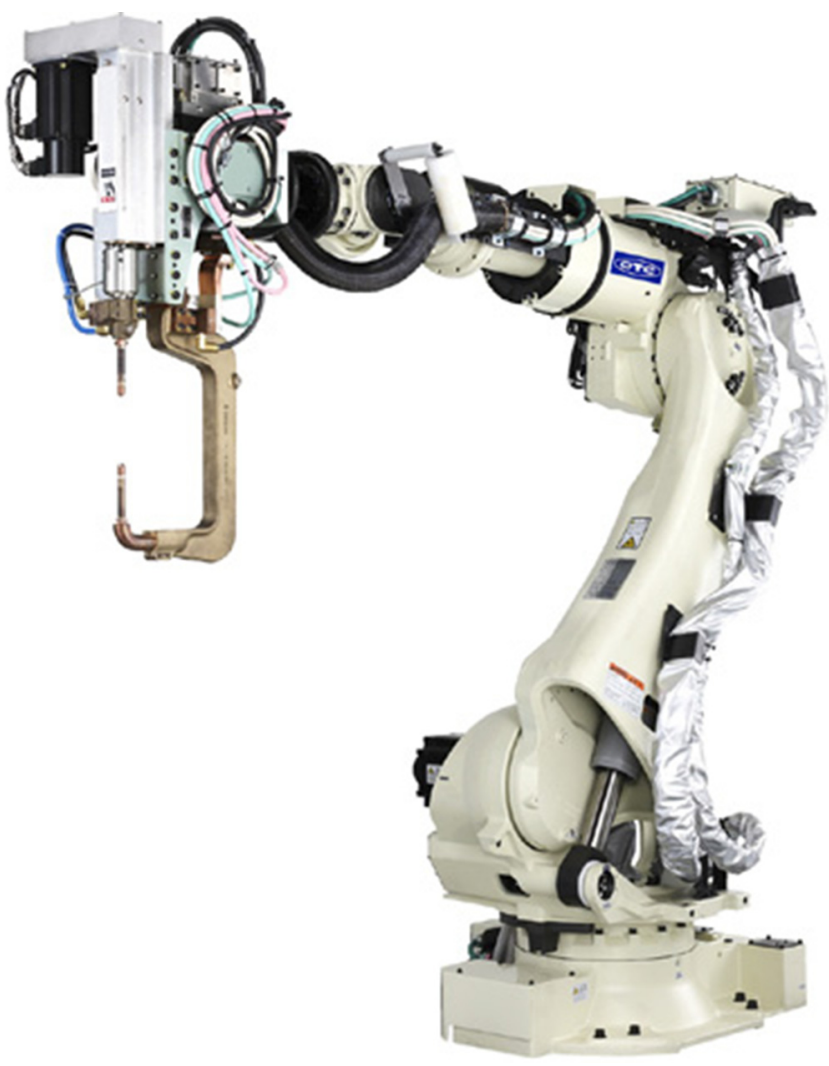

Fig. 1. Example of resistance spot welding gun attached to robot [2].

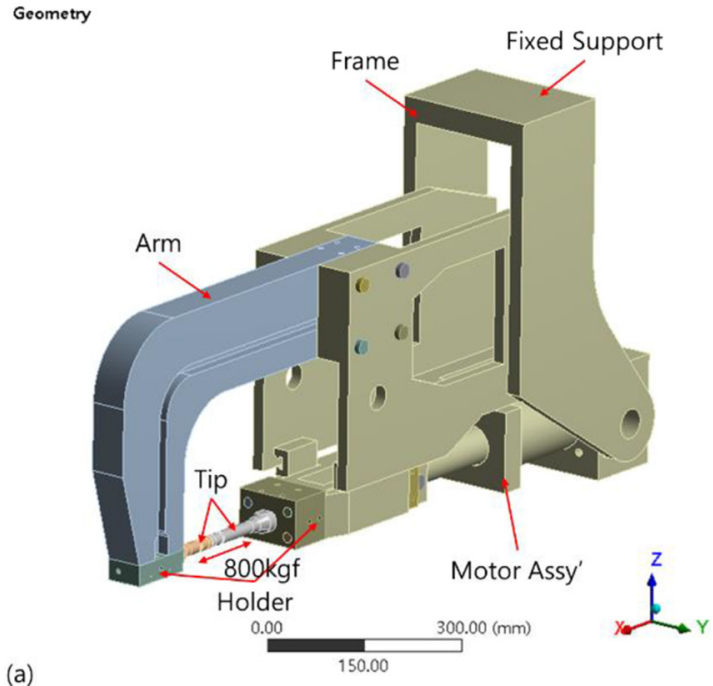

as shown in Figure 2, and the tip of the motor assembly is pressurized to the tip connected to the arm. The $\mathrm{C}$ type welding gun is as shown in Figure 2a, and the frame is a common module. A force of $800 \mathrm{kgf}$ is applied to the tips of the both ends, and the plate attached to the multi-joint robot is used as a fixed condition. As shown in Figure 2b, the frame of $\mathrm{X}$ type consists common module and adding two rotating parts, and applies two each of tip, holder, and arm. The boundary condition is performed by motor assembly to pressurize the arm and the welding is performed. The material properties used for the optimization for the RSW gun have been given in Table 1 . As a welding gun material, aluminum alloy (6065-T651) are used for frames and arm, brass castings (C18200) are used for tips and KMS 10 are used for holders. For bolts used between frame and arm, arm and holder, preload is calculated and applied to bolt specifications, and preloads corresponding to each specification are shown in Table 2.

\subsection{Boundary condition and analysis result}

In the case of the $\mathrm{C}$ type, a pressing force of $800 \mathrm{kgf}$ is directly transmitted to the frame to perform a static analysis, and in the case of the $\mathrm{X}$ type, the reaction force changes according to the movement of the modular frame, so that the transient analysis is performed. The results of the stress and the amount of deformation when the force of $800 \mathrm{kgf}$ is applied to each tip of the welding gun are shown in Figure 3. The $\mathrm{C}$ type stress and deformation results are shown in Figure 3a. The stress is higher in the location

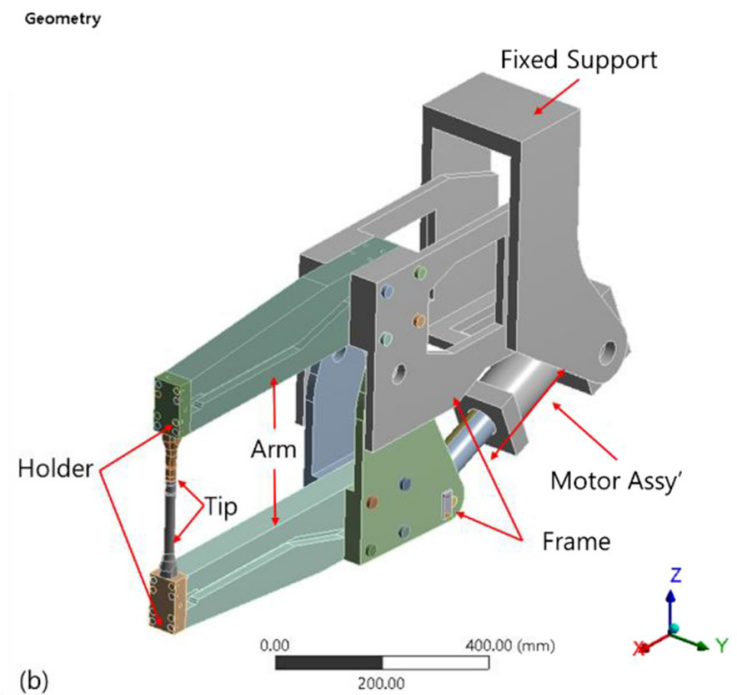

Fig. 2. Images of resistance spot welding gun geometry and boundary condition: (a) C type, and (b) X type.

Table 1. Properties of material.

\begin{tabular}{llllll}
\hline Material & $\begin{array}{l}\text { Density } \\
{\left[\mathrm{mm} / \mathrm{kg}^{2}\right]}\end{array}$ & $\begin{array}{l}\text { Young's Modulus } \\
{[\mathrm{MPa}]}\end{array}$ & $\begin{array}{l}\text { Poisson } \\
\text { ratio }\end{array}$ & $\begin{array}{l}\text { Yield Strength } \\
{[\mathrm{MPa}]}\end{array}$ & $\begin{array}{l}\text { Tensile Strength } \\
{[\mathrm{MPa}]}\end{array}$ \\
\hline $6065-\mathrm{T} 651$ & 2710 & 68.647 & 0.33 & 245 & 295 \\
C18200 & 8890 & 130.090 & 0.30 & 379 & 448 \\
KMS10 & 8900 & 104.900 & 0.33 & 294 & 490 \\
\hline
\end{tabular}


Table 2. Pre-load according to bolt specification.

\begin{tabular}{lcllc}
\hline Bolt & Tightening Torque $[\mathrm{Nm}]$ & Diameter $[\mathrm{mm}]$ & Torque constant & Pre-load $[\mathrm{N}]$ \\
\hline M16 & 183.0 & 16 & 0.2 & 57.187 \\
M12 & 74.0 & 12 & 0.2 & 30.833 \\
M8 & 21.4 & 8 & 0.2 & 13.375 \\
M6 & 8.8 & 6 & 0.2 & 7.333 \\
\hline
\end{tabular}
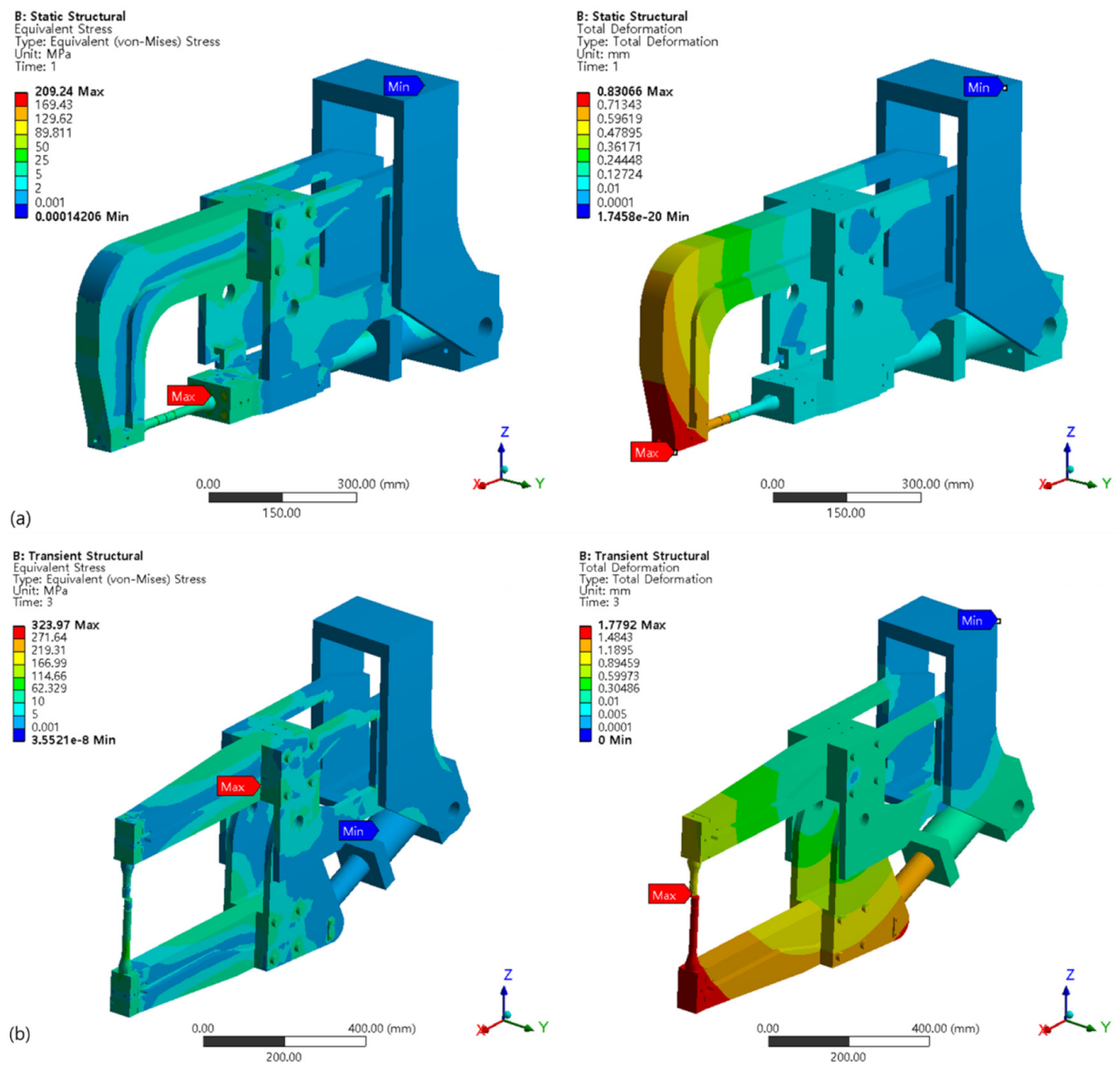

Fig. 3. FEA result of welding gun model under $800 \mathrm{kgf}$ of force von-mises stress and total deformation: (a) $\mathrm{C}$ type, and (b) X type.

where the pressing is performed than the frame attached to the robot, but it is lower than the allowable stress of each material. The maximum stress area appears at the bolt location that connects the motor mount and holder. At this time, the maximum stress is $209.24 \mathrm{MPa}$, and the strength of the bolt larger than $240 \mathrm{MPa}$ is selected. The maximum position of deformation is shown in the holder connected to the arm, measured in small quantities at $0.83 \mathrm{~mm}$. The $\mathrm{X}$ type stress and deformation results are shown in Figure $3 \mathrm{~b}$. The location of maximum stress is the bolt where the upper arm and the frame connected, the stress is $323.97 \mathrm{MPa}$.
The stress of the frame, arm, and tip, which are the positions to be pressured, but the other parts are lower than the allowable stress of each material. The strength of the bolt is higher than $345 \mathrm{MPa}$. The maximum location of the deformation is indicated by the holder and tip connected to the lower arm, measured at $1.73 \mathrm{~mm}$.

\section{Optimization}

In order to minimize the weight of the welding gun frame, size optimization is performed. The three positions of the 
modular frame are set as variables used for size optimization. The location of variables is shown in Figure 4. The actual thickness of the variable is set to the upper limit, and the lower limit is set to $-20 \%$ of the current thickness. The objective function is specified as the weight minimization of the welded gun frame, and the stress result of the frame is set as the limiting condition so as not to

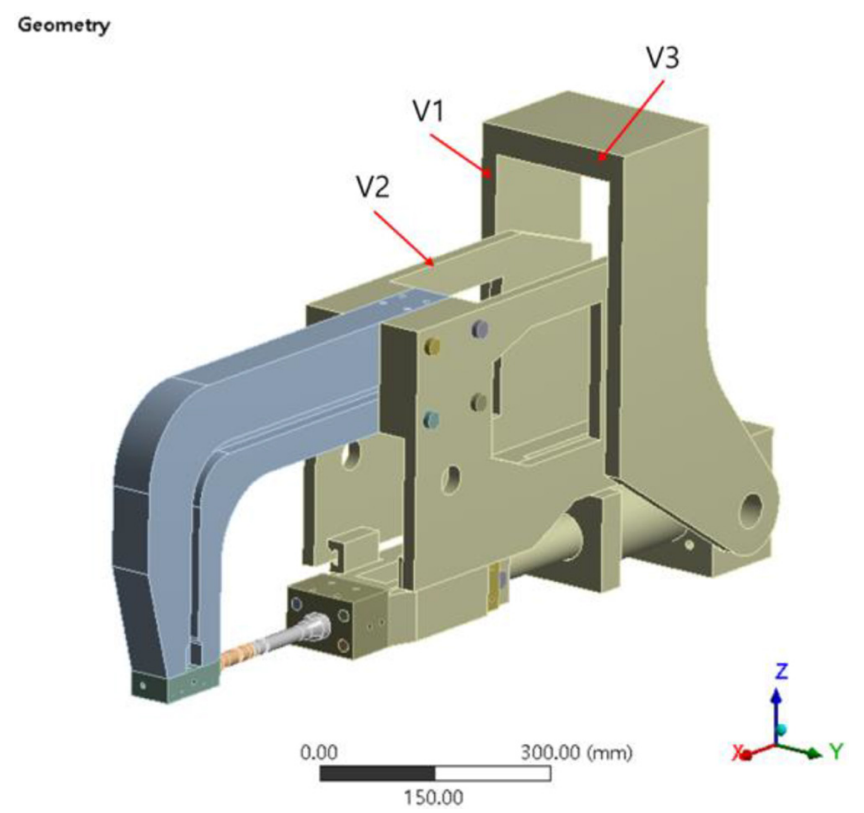

Fig. 4. Variable location for size optimization. exceed the allowable aluminum stress of $245 \mathrm{MPa}$. Equation (1) shows the size optimization conditions frame of RSW gun.

$$
\begin{aligned}
& \text { Design Variable: Thickness of parts } \\
& \text { objective: Minimize Mass } \\
& \text { subject to: } \sigma_{\max } \leq 245 \mathrm{MPa} \\
& \text { side constraints: }-20 \%<\text { thickness }(\mathrm{t})
\end{aligned}
$$

Genetic algorithm (GA) based objective optimization is performed for the configured responses to the optimized points. GA is used for size optimization. GA is one of the global optimization techniques and can solve various problems $[9,10]$. The optimization results are shown in Table 3 and Figure 5 . The stress value of the $\mathrm{C}$ type welding gun analysis result is the maximum stress point at the same position as the original model, as shown in Figure 5a. The deformation amount is $0.886 \mathrm{~mm}$, as shown in Figure $5 \mathrm{~b}$, which is about $0.06 \mathrm{~mm}$ difference from the original model, and the maximum deformation location is shown in the holder connected to the arm. The weight of the size optimized model is reduced by $25 \%$ than the original model, and the frame and other parts excluding the highest stress area are lower than the allowable stress of each material. The deformation amount is $1 \%$ difference, and it is considered that the welding quality is not greatly affected.

Most of the frames, including the plate that mounted on the multi-joint robot, show stresses of less than $50 \mathrm{MPa}$. A new design is proposed through topology optimization for over-designed frames. In the model where the size optimization is performed, the entire frame excluding

Table 3. Variable thickness and frame weight for optimization results.

\begin{tabular}{lllll}
\hline Variable & V1 & V2 & V3 & Frame \\
& Thickness $[\mathrm{mm}]$ & Thickness $[\mathrm{mm}]$ & Thickness $[\mathrm{mm}]$ & Weight $[\mathrm{kg}]$ \\
\hline Original & 25.00 & 20.00 & 40.00 & 39.51 \\
With size optimization & 17.00 & 16.00 & 31.00 & 29.91 \\
\hline
\end{tabular}
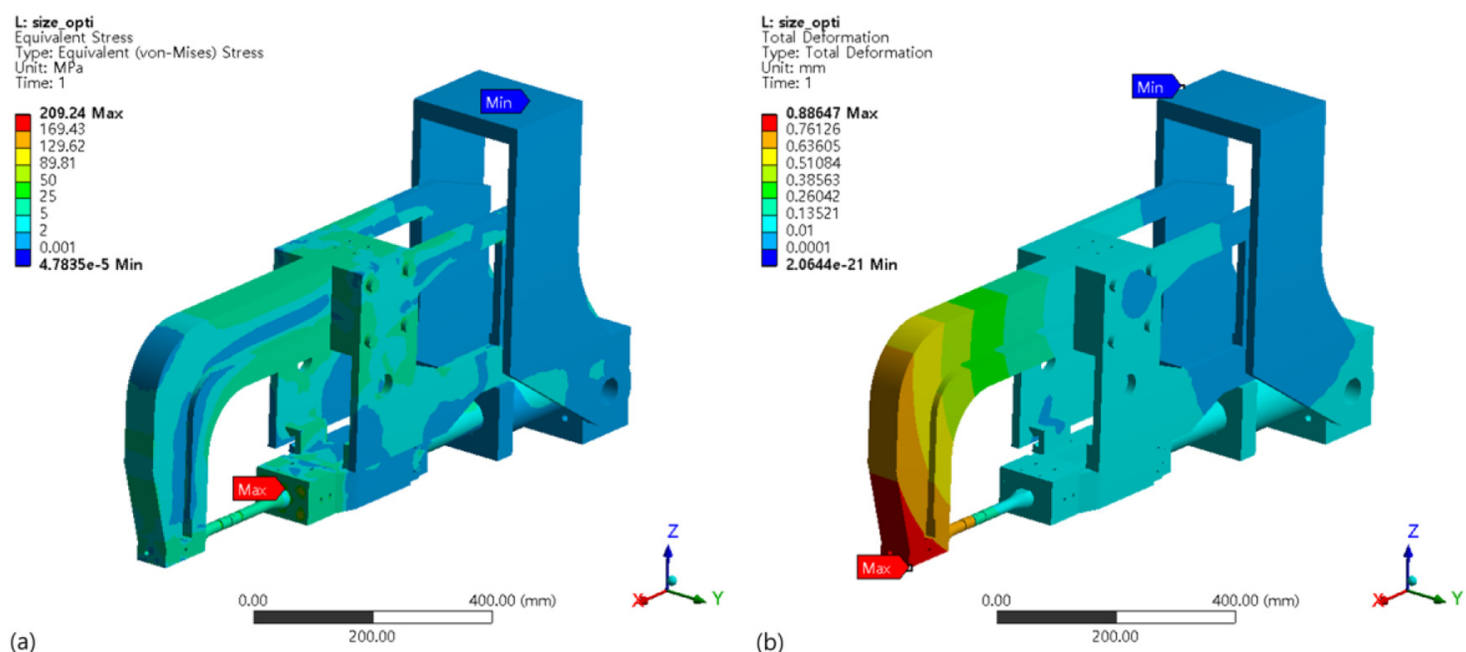

Fig. 5. FEA result of welding gun model with size optimization under $800 \mathrm{kgf}$ of force: (a) von-mises stress, and (b) total deformation. 
Geometry

(a)

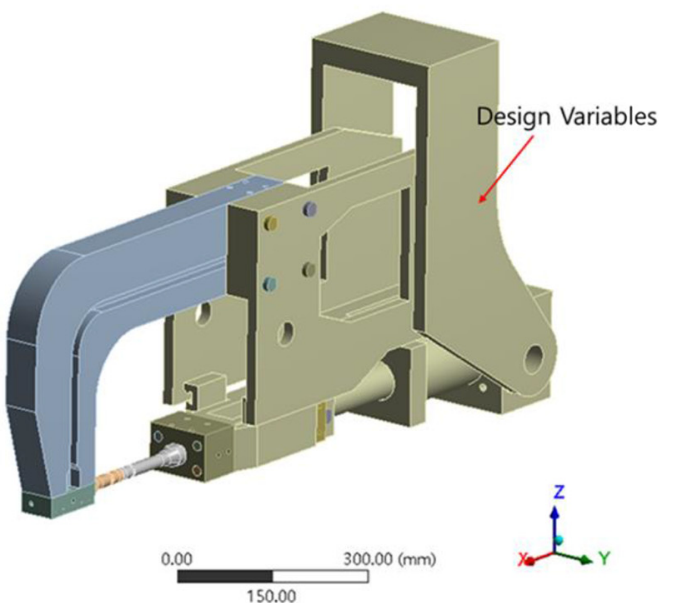

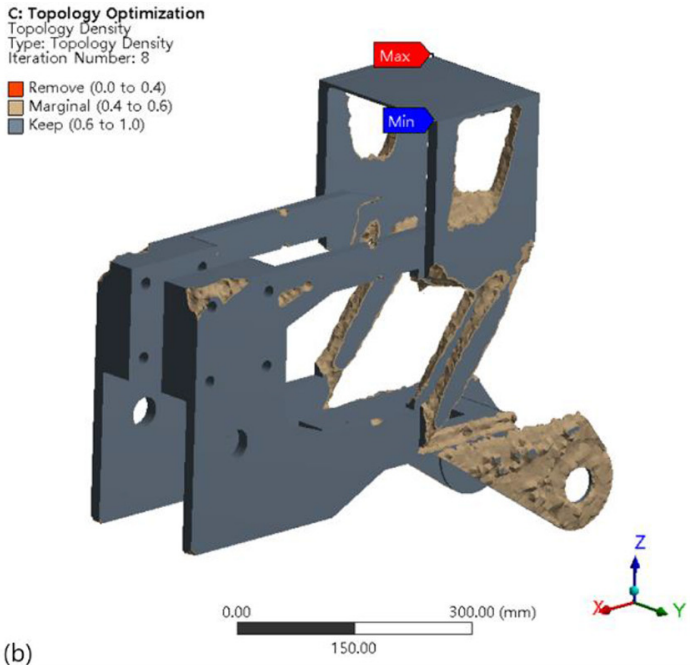

(b)

Fig. 6. Topology optimization of the $\mathrm{C}$ type resistance welding gun: (a) design variables, and (b) optimization result.

Geometry

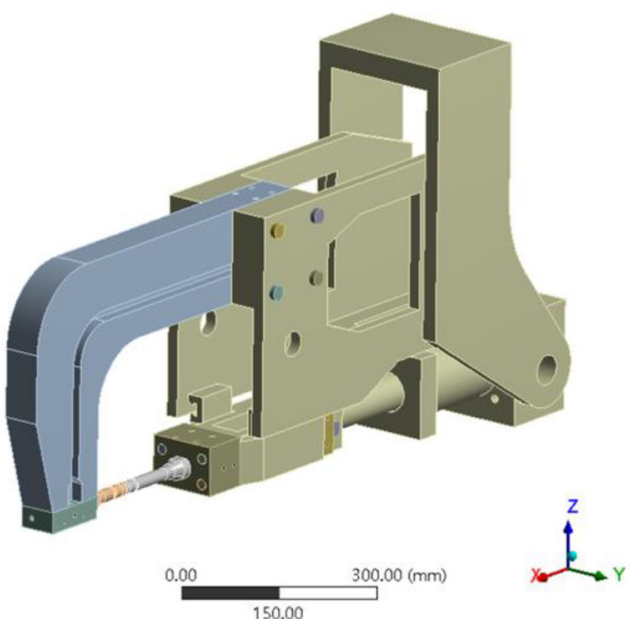

Geometry

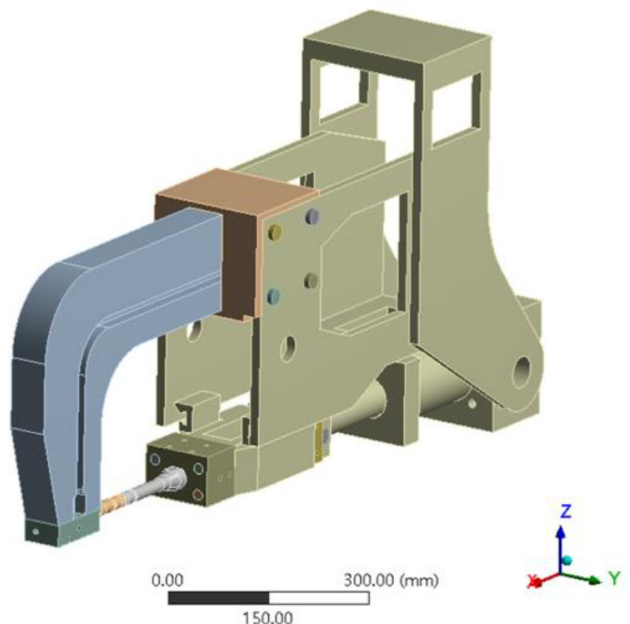

Fig. 7. Geometry model of $\mathrm{C}$ type with modular frame: (a) original model and (b) final model.

the plate mounted on the robot is set as a design variable. The objective is to minimize the compliance, and the result of the topology optimization should be symmetrical. Equation (2) shows the topology optimization conditions frame of RSW gun.

Design Variable: Frame shape objective: Minimize Complinacne subject to: $\sigma_{\max } \leq 245 \mathrm{MPa}$ side constraints: Mass retain, $60 \%$ Symmetry $Y$ - axis

Figure 6a shows the design variables of the C type RSW gun. Design variable is the modular frame of RSW gun, and the result of topology optimization is shown in Figure 6b. The result of topology optimization is modified by the compatibility of $\mathrm{C}$ type and $\mathrm{X}$ type and reflected within the range of possible design changed. The range where design changes are possible and brackets to prevent deformation of the arm are added and reflected in the final model. The added bracket increases the weight of the modular frame than the optimization result. Figure 7 shows the original model of $\mathrm{C}$ type with modular frame applied and the design changed final model. The final model is optimized for size, topology optimization, and the addition of brackets to the arm and frame connections to reduce stress The results of the analysis of the final model are shown in Figure 8, and the maximum position of the $\mathrm{C}$ type stress appears to be $263.98 \mathrm{MPa}$ in the bolt connecting the arm and the holder. The amount of deformation is $1.84 \mathrm{~mm}$ in the tip connected to the arm. The maximum position of the $\mathrm{X}$ type stress is $432.18 \mathrm{MPa}$ in the bolt connecting the pressing arm and frame, and the deformation amount is $1.57 \mathrm{~mm}$ in the holder connected to the pressing arm. Table 4 compares the weights of three $\mathrm{C}$ type and $\mathrm{X}$ type models. In the $\mathrm{C}$ type original model using the modular 

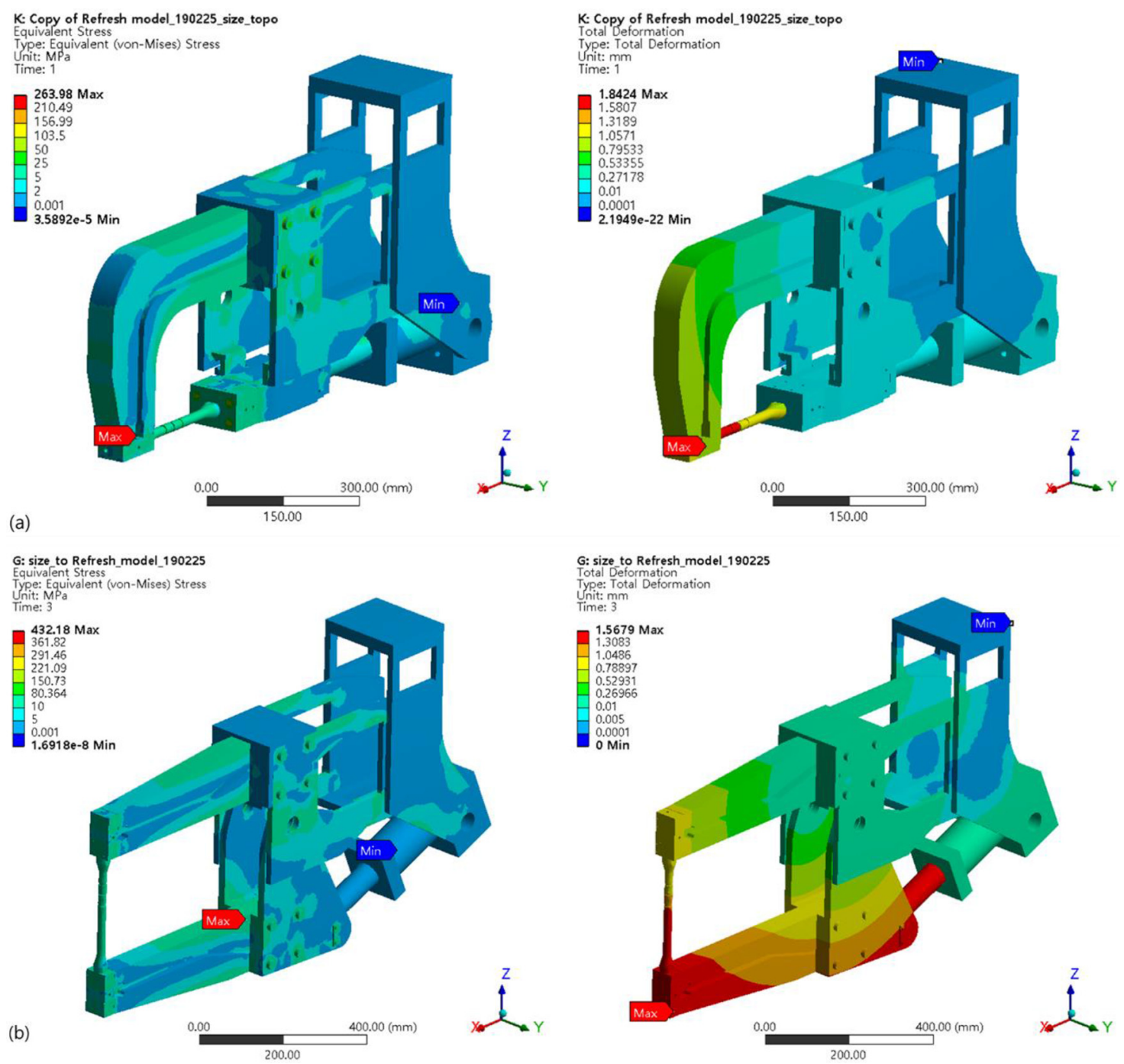

Fig. 8. FEA result of Final welding gun model under $800 \mathrm{kgf}$ of force von-mises stress and total deformation: (a) $\mathrm{C}$ type and (b) X type.

Table 4. Comparison of original model and optimized model frame analysis results.

\begin{tabular}{llllll}
\hline & Von-mises stress $[\mathrm{MPa}]$ & $\begin{array}{l}\text { Deformation } \\
{[\mathrm{mm}]}\end{array}$ & $\begin{array}{l}\text { Mass } \\
{[\mathrm{Kg}]}\end{array}$ & $\begin{array}{l}\text { Reduction } \\
{[\%]}\end{array}$ \\
\hline \multirow{4}{*}{ C Type } & Original & 209.24 & 0.831 & 39.51 & - \\
& Size Optimized & 209.24 & 0.886 & 29.91 & 24.3 \\
& Final model & 263.98 & 1.842 & 32.06 & 18.9 \\
& Original & 323.97 & 1.783 & 52.87 & - \\
& Size Optimized & 353.68 & 1.5951 & 42.87 & 18.91 \\
& Final model & 432.18 & 1.568 & 45.02 & 14.85 \\
\hline
\end{tabular}

frame, the size optimization model reduced the weight by $25 \%$, but the final model increased the weight by $32 \mathrm{~kg}$ compared to the size optimization model by about $2 \mathrm{~kg}$ due to the addition of the bracket. In $\mathrm{X}$ type, the additional frame weight of $12.96 \mathrm{~kg}$ is added, so the size optimization model is reduced by $20 \%$ and the final frame weight is $45.02 \mathrm{~kg}$.

\section{Experiment}

\subsection{Experiment set up}

When the welding gun applies constant pressure to the tip, high current is energized to generate heat inside the member, and it melts, and the nugget is generated [11]. 
(a)
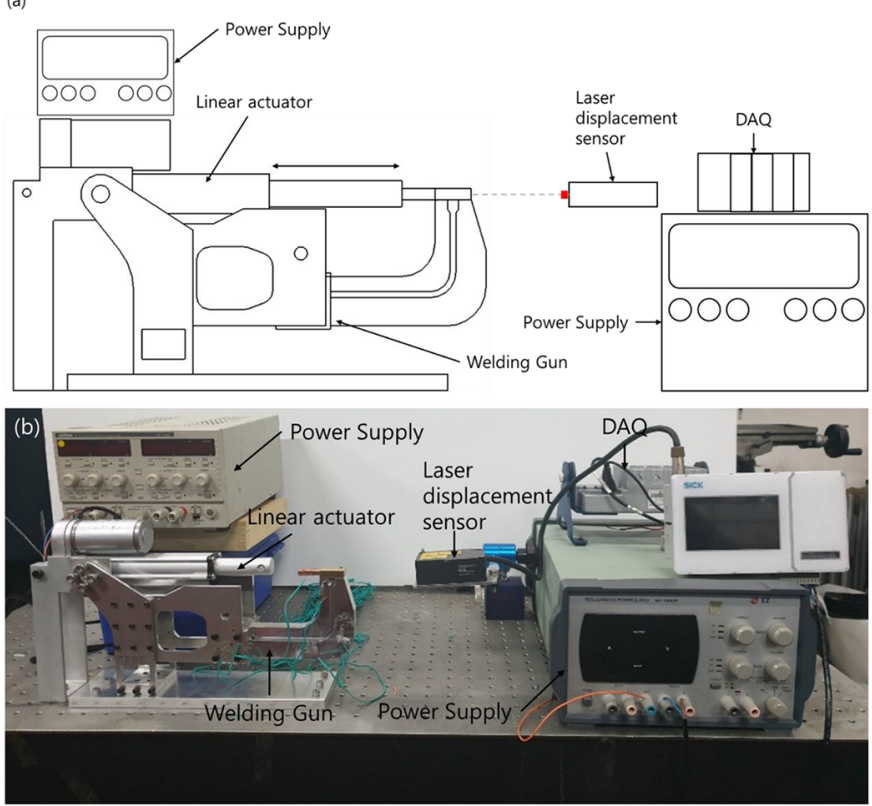

Fig. 9. Experimental set up: (a) schematic diagram, and (b) photograph of the RSW gun tester.

During this process, structural stress and deformation are generated in the frame when pressurization is performed. Experiments are carried out to verify the structure of the optimized weld gun when pressurized. The experimental device is designed and constructed in an environment similar to the conditions under which welding is carried out. The actual size of the weld gun is large enough to be experimentally constructed with a $1 / 4$ downscale. The experimental setup is shown in Figure 9 [12]. The schematic diagram of the experimental apparatus is shown in Figure 9a, and the actual experimental device is shown in Figure 9b. The experimental setup consists of RSW gun, linear actuator, power supply, laser displacement sensor, and DAQ. The power supply drives the linear actuator, and the laser displacement sensor, the welding gun, and motor bracket are installed on the hard table, and the experiment data is collected on the computer through DAQ. Each transducer is calibrated for accurate measurement. The experimental equipment uses aluminum alloy (6065-T651), brass casting (C18200), and KMS10, reflecting the material used for the analysis. At downscale, bolt sizes have been changed to M4, M3, and M2.

\subsection{Downscale experiment}

For the downscale experiment, an actual $800 \mathrm{kgf}$ force is replaced with a force of $60 \mathrm{kgf}$ and $40 \mathrm{kgf}$, and a linear actuator is used to pressurize the tip attached to the arm. The force applied by the linear actuator is measured by a push-pull gauge. A laser displacement sensor is installed at the same height as the tip to measure the deformation amount of tip and arm when pressurized. In Figure 10, in order to make the angle of the actuator equal to the analysis in the $\mathrm{C}$ type and $\mathrm{X}$ type, the holder is changed and used. $\mathrm{C}$ type connects the holder directly as an actuator is
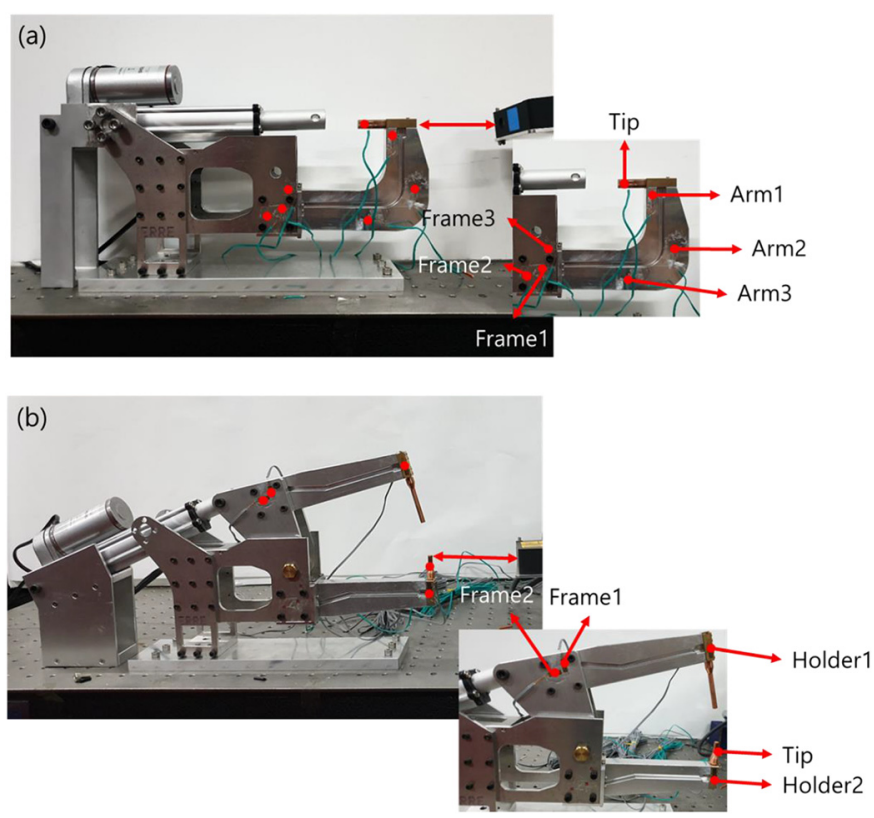

Fig. 10. Strain gauge measurement and laser displacement sensor location: (a) $\mathrm{C}$ type and (b) $\mathrm{X}$ type.

connected to a modular frame, and $\mathrm{X}$ type uses an inclined holder to connect the actuator to the added plate. The strain gauges of $\mathrm{C}$ type welding gun are installed in seven locations, three in the frame, three in the arm, and one in the tip, as shown in Figure 10a. Frame is installed near the connecting bolts of the arm and frame, and the arm is installed at the point of curvature where damage is expected. The strain gauge location of $\mathrm{X}$ type welding gun is shown in Figure 10b. Two in the frame, one in the two holders, and one in the tip. The frame is installed near the bolt connecting the arm and the frame and the holder and tip are installed at the point where the stress is expected to be high. The pressurization is performed five times to reflect the repetition of resistance spot welding. Experimental data are collected through the DAQ and laser displacement sensor at each pressurization. The stress at the attachment site is obtained through the strain measured by the strain gauge, and the displacement at the maximum displacement position is measured through the laser displacement sensor. Both $\mathrm{C}$ type and $\mathrm{X}$ type using a modular frame are tested through experiments, and the experimental and analysis results are compared. Based on the strain value obtained at the strain gauge position shown in Figure 9, the stress value corresponding to the position is derived, and the derived stress value is compared with the analytical value.

\section{Result and discussion}

During the scale down experiment, the amount of deformation of the tip and the structural stress are measured to verify the structure of the optimized weld gun. The stress value gained from the $\mathrm{C}$ type experiment is black in Figure 11a and the figure means the experimental 

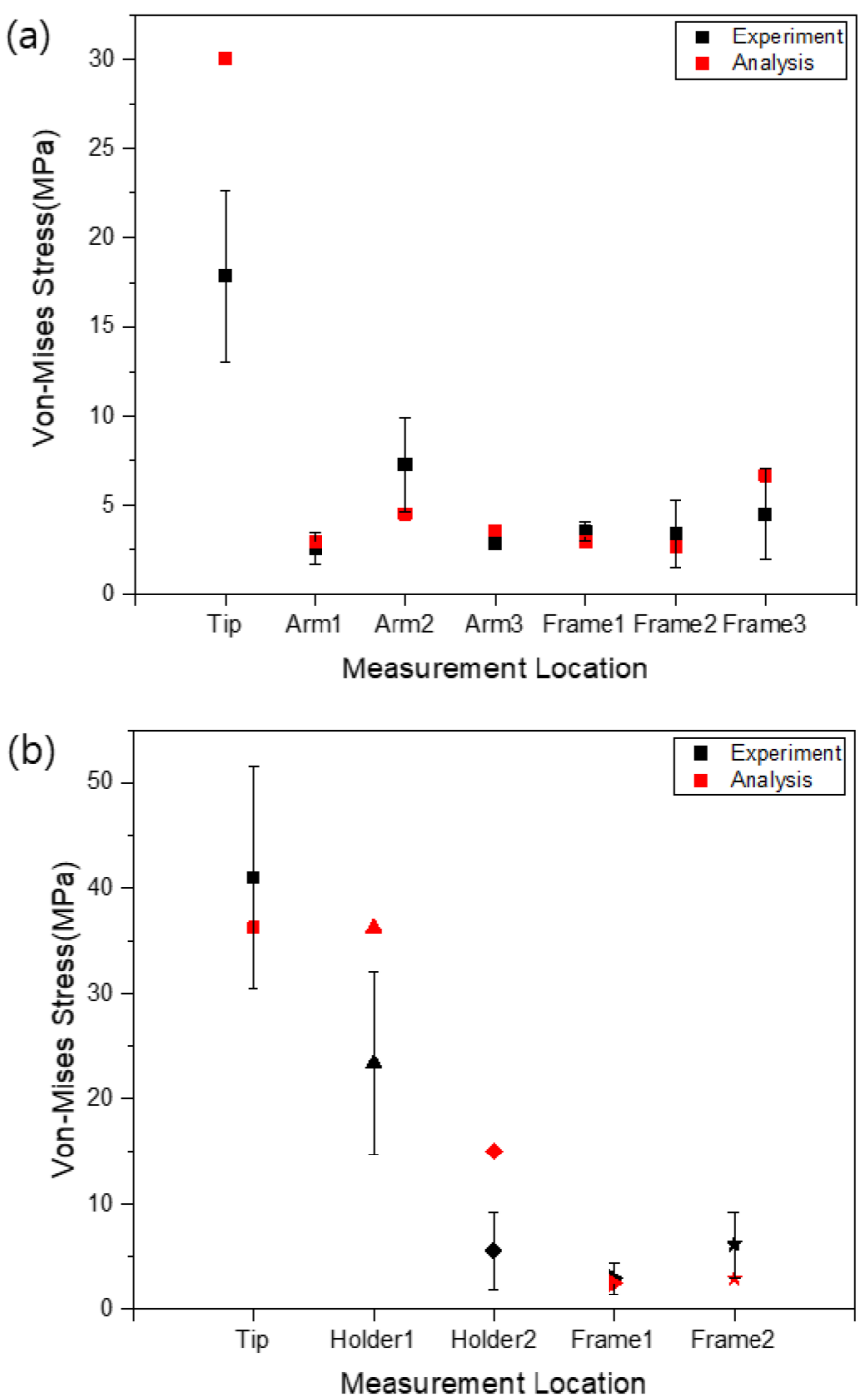

Fig. 11. Graph of experiment and analysis results comparison for final model: (a) $\mathrm{C}$ type and (b) $\mathrm{X}$ type.

value average. Red means analytical value at $1 / 4$ scale of $60 \mathrm{kgf}$. The $\mathrm{X}$-axis is the measuring location, and $\mathrm{Y}$-axis is the von-mises stress. Experimental results show that 'Tip' is the part to be pressurized and $17 \mathrm{MPa}$ appears at higher stress than other locations. 'Arm1' appears to be connected to the arm and holder at about $3 \mathrm{MPa}$, and 'Arm2', which is expected to be broken in the arm, appears to be $7 \mathrm{MPa}$, which is next to 'Tip'. The last 'Arm3' in the arm is 2.8 MPa. The stress of 'Frame1', 'Frame2', and 'Frame3' near the connecting bolt of the arm and frame, where the stresses were derived from the analysis, were calculated to be $3.5 \mathrm{MPa}, 3.4 \mathrm{MPa}$ and $4.5 \mathrm{MPa}$, respectively. The results of the analysis show that about $30 \mathrm{MPa}$ in 'Tip' and about $3 \mathrm{MPa}$ in 'Arm1', which is connected to the arm and the holder, and 'Arm2', which is expected to be broken, are $5 \mathrm{MPa}$ and $3.5 \mathrm{MPa}$, respectively. The analytical stresses of 'Frame1', 'Frame2', and 'Frame3' near the connecting bolt of arm and frame are $2.9 \mathrm{MPa}, 2.8 \mathrm{MPa}$ and $6.7 \mathrm{MPa}$, respectively. As a result, except for 'Tip', the average result of the experiment and the analysis result are different by about $20 \%$. However, since the analysis result is shown between the experimental results, the optimization model is verified through the experiment. The stress value derived from the $\mathrm{X}$ type experiment is black in Figure 11b, and the shape means the average of the experimental values. Red means analytical value at $1 / 4$ scale of $40 \mathrm{kgf}$. Experimental results show that $5.61 \mathrm{MPa}$ is shown by the stress of 'Holder1' which is the holder part of the pressurizing arm and 'Holder2' which is the holder part of pressurized arm has 23.38 MPa with higher stress than 'Holder1'. The 'Tip' stress at the pressurized arm is $40.99 \mathrm{MPa}$. 'Frame1' and 'Frame2' near the bolt position where the stress is highest in the analysis are calculated as $3.00 \mathrm{MPa}$ and $6.18 \mathrm{MPa}$, respectively. The analysis results are shown to be 16.24 MPa at the pressurized part 'Holder1' and $36.26 \mathrm{MPa}$ at the pressurized part 'Holder2' and 'Tip', respectively. $3 \mathrm{MPa}$ is shown in 'Frame1' and 'Frame2' located near bolts where stress is high, and stress in the holder and tip section is shown to have $30 \%$ error in the average result and interpretation result of the experiment. Considering the error of strain gauges that occur during the test, experimental results can be used.

\section{Conclusion}

In this study, structural analysis and optimization of resistance spot welding gun are performed and the optimized model is verified through experiments. The optimization and experimental verification are performed on the modular frame of the weld gun. The $\mathrm{C}$ type and the $\mathrm{X}$ type are tested, and the experimental results are compared and verified. The common modular frame is $32.06 \mathrm{~kg}$, reduced about $20 \%$ from $39.91 \mathrm{~kg}$. The maximum stress point results for the original and final models are bolts connecting the arm and frame. The stress on other structures except for the maximum stress point is lower than the allowable stress of the material. When the numerical values of stress and deformation are considered, the quality of welding is expected to be improved because the final model has a smaller value than the original model. The reduction of the payload of the multi-joint robot has been achieved through the weight reduction of the welding gun. Therefore, it is verified through analysis and experiment that the production cost is reduced, the efficiency of the multi-joint robot is increased, and the welding quality is not greatly influenced by other attachments depending on the welding situation.

This research was supported by a grant from the Advanced Technology Center R\&D Program funded by the Ministry of Trade, Industry \& Energy of Korea (No. 10077267).

\section{References}

1. D. Spinella, J.R. Brockenbrough, J.M. Fridy, Trends in aluminum resistance spot welding for the auto industry, Welding J. 84, 34-40 (2005)

2. OTC Spot Welding Robot, DTool, 06, 07, 2019, https:// dtoolthailand.com/Product/list/cat/6/scat/6/sscat/9 
3. A. Ambroziak, M. Korzeniowski, Using resistance spot welding for joining aluminium elements in automotive industry, Arch. Civil Mech. Eng. 10, 5-13 (2010)

4. F. Khodabakhshi, M. Kazeminezhad, H.-A. Kokabi, Resistance spot welding of ultra-fine grained steel sheets produced by constrained groove pressing: optimization and characterization, Mater. Character. 69, 71-83 (2012)

5. K. Zhou, P. Yao, Overview of recent advances of process analysis and quality control in resistance spot welding, Mech. Syst. Signal Process. 124, 170-198 (2019)

6. M. Poiranvari, Fracture toughness of martensitic stainless steel resistance spot welds, Mater. Sci. Eng A 680, 97-107 (2017)

7. W. Mazur, A. Kyriakopoulos, N. Bott, D. West, Use of modified electrode caps for surface quality welds in resistance spot welding, J. Manufactur. Process. 22, 60-73 (2016)
8. H. Tang, H. Hou, S.J. Hu, Influence of welding machine mechanical characteristics on the resistance spot welding process and weld quality, Weld J. 5, 116-124 (2003)

9. M. Viqaruddina, D. Reddy, Structural optimization of control arm for weight reduction and improved performance, Mater. Today: Proc. 4, 9230-9236 (2017)

10. T. Usman, M. Hyder, Optimization of the size and shape of the set-in nozzle for a PWR reactor pressure vessel, Nucl. Eng. Des. 284, 219-227 (2015)

11. T.S. Hong, M. Ghobakhloo, W. Khaksar, Robotic welding technology, Comprehens. Mater. Process. 6, 77-99 (2014)

12. A. Sutradhar, J. Park, M.J. Miller, Experimental validation of 3D printed patient-specific implants using digital image correlation and finite element analysis, Comput. Biol. Med. 52, 8-17 (2014)

Cite this article as: Ji-Su Hong, Kwang-Hee Lee, Chul-Hee Lee, The frame optimization and validation of resistance spot welding gun, Int. J. Simul. Multidisci. Des. Optim. 11, 22 (2020) 